\title{
Cutaneous nodules as a primary manifestation of carcinoma stomach
}

\author{
Sanjay Marwah ${ }^{1}$, Siddharth Pandey ${ }^{1}$, Hem Kant Verma ${ }^{1}$, Mahavir Singh ${ }^{1}$ and Nisha Marwah $^{2}$ \\ ${ }^{1}$ Department of Surgery, Post graduate Institute of Medical Sciences, India \\ ${ }^{2}$ Department of Pathology, Post graduate Institute of Medical Sciences, India
}

\begin{abstract}
A middle aged male presented with brownish skin discoloration with itching and nodular skin eruptions on the anterior abdominal wall of eight months duration. Dermatological examination revealed hyperpigmented and thickened abdominal wall skin with multiple small cutaneous nodules that were diagnosed as allergic dermatitis. He was treated with topical steroids and antiallergic drugs with no response. Skin biopsy after four weeks made the diagnosis of signet ring cell carcinoma that came out to be metastasis from carcinoma stomach on further investigations. This case is being reported for the rare presentation of gastric carcinoma as cutaneous nodules.
\end{abstract}

\section{Introduction}

Skin metastasis is known to occur in various neoplastic lesions. Large reviews suggest that $6.4 \%$ of all malignancies have skin involvement at some point of time [1]. Whenever the metastasis is from gastro intestinal tract, colon is the commonest site for primary tumor followed by stomach, esophagus and small intestine. However, cutaneous metastasis of gastric cancer is relatively rare [2,3]. The occurrence of same could be either synchronous or metachronous with the primary. We report a rare case of gastric adenocarcinoma presenting to the dermatologist with cutaneous nodules as the only presenting feature.

\section{Case report}

A 45 year old male came to the skin OPD with complain of brownish discoloration of abdominal skin with itching since 8 months and nodular skin eruptions in the abdomen since 4 months (Figure 1). He was provisionally diagnosed with allergic dermatitis and treated with topical steroid ointment and systemic anti-allergic drugs but without any response. After four weeks, skin biopsy was taken which revealed signet ring cell carcinoma which stained positive for PAS and cytokeratin (Figures $2 \mathrm{a}$ and $2 \mathrm{~b}$ ). Patient was referred to the Department of Surgery. On examination there was dark brownish discolouration and thickening of skin in mid and lower abdomen anteriorly and at the back. There were multiple, small, skin colored, nontender, firm nodules adherent to the overlying skin in right paraumbilical region over an area of $5 \times 5 \mathrm{~cm}$ and on the left flank in $1 \times 1 \mathrm{~cm}$ area. There was no palpable lump or organomegaly. On abdominal ultrasound, mural thickening of stomach was seen. Contrast enhanced CT scan of the abdomen showed diffuse thickening of antral and body regions of the stomach suggestive of carcinoma of stomach. Upper GI endoscopy revealed thickened gastric wall in body and antrum, biopsy was taken which was suggestive of moderately differentiated adenocarcinoma. Subsequently, the patient developed nausea and abdominal pain. In view of advanced disease, the patient was given palliative chemotherapy (ECF regimen). Epirubicin and Carboplatin was given on day 1 followed by daily infusion of 5-FU for 21 days. However, his condition deteriorated and he died within four months of his presentation.

\section{Discussion}

Cutaneous metastasis may rarely be the first sign of malignancy. However it is often missed because it usually mimics common dermatological conditions and there is lack of awareness of this clinical entity. It may occur due to direct spread from underlying malignancy, lymphatic spread or hematogenous spread from a distant primary tumor.

Tumors spreading through hematogenous route (kidney, lung)

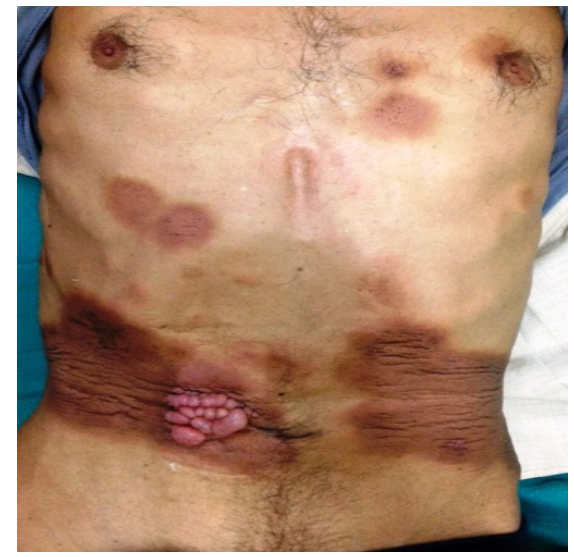

Figure 1. Clinical photograph showing patches of brownish discoloration and periumbilical skin nodules.

Correspondence to: Dr. Sanjay Marwah, 2452, Sector I, HUDA, Rohtak, Haryana, India-124001, Tel: +91 9416336886; E-mail: drsanjay.marwah@gmail.com

Key words: cutaneous metastasis, gastric carcinoma, primary presentation

Received: February 03, 2015; Accepted: March 09, 2015; Published: March 12, 2015 


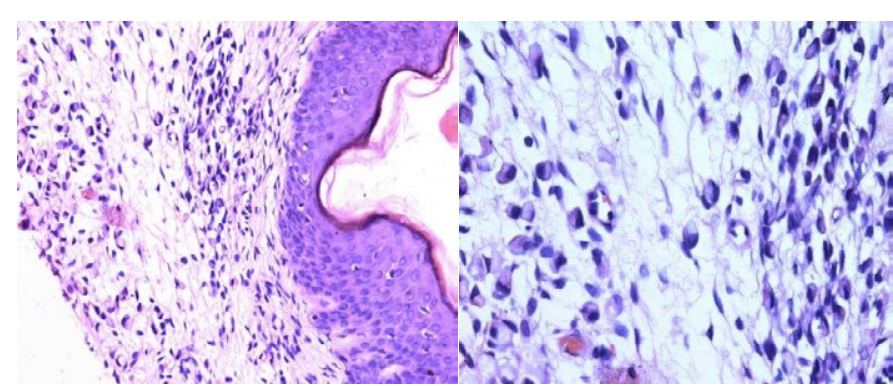

Figure 2. a. Microphotograph showing epidermis covered dermis revealing infiltration by signet ring cells ( $\mathrm{H} \& \mathrm{E}$ x 20X). b. Microphotograph showing cells with abundant amount of pale pink clear cytoplasm with nucleus pushed to periphery (H \& E x 40X).

often present with cutaneous metastasis at a distant site from primary lesion whereas tumors spreading through lymphatic route (breast, oral cancer) tend to appear later in the course of disease and usually involve the skin overlying primary tumor [4]. Non-specific, painless dermal or subcutaneous nodule is the most common presentation of a cutaneous metastasis [5]. In men cutaneous metastasis are reported to occur in lung cancer, colon cancer, melanoma, squamous cell carcinoma of the oral cavity, and renal cell carcinoma whereas in women, common sites are breast cancer, colon cancer, melanoma, ovarian cancer, and lung cancer [2]. Thus in patients with cutaneous metastasis, breast is the most common site of primary in women and lung in men [6]. Primary tumors arising from upper GI tract are less than $1 \%$ in cases of cutaneous metastasis [7].

Gastric carcinoma is one of the commonest causes of death from cancer. Weight loss and persistent abdominal pain are the usual symptoms at initial diagnosis of carcinoma of stomach. On examination, palpable abdominal mass is the most common physical finding and generally indicates long standing, advanced disease. Gastric carcinoma usually metastasizes to liver, regional lymph nodes and peritoneal cavity whereas cutaneous metastasis is an unusual presentation. Overall cutaneous metastasis is reported to occur in $0.8 \%$ cases of gastric cancer [8]. Cutaneous metastases are usually reported to be close to the site of the primary tumor, therefore abdomen is the most frequent site of involvement in gastric cancer [4]. Sister Mary Joseph's nodule at umbilicus is the typical site of cutaneous metastasis in gastric cancer. Skin metastasis in carcinoma stomach can also present as a nodule, cellulitis or as carcinoma erysipelatoides (ill-defined area of warm, tender, erythematous and edematous skin) [5,9]. The latter closely mimics acute infective pathology (cellulitis, erysepilas) but there is absence of fever, chills and leucocytosis.

Prognosis in carcinoma stomach is variable depending upon metastasis to other organs but in the majority of cases, cutaneous metastasis indicates poor survival as happened in the present case. However in patients with isolated cutaneous metastasis, long-term survival after systemic therapy has sometimes been reported [10].

In conclusion, dermatological manifestation of carcinoma stomach as primary presentation is very unusual. However, the possibility of cutaneous lesions as a manifestation of systemic malignancy should be kept in mind as a differential diagnosis by the dermatologists while dealing with such cases so that early diagnosis and timely intervention can help in improving overall patient survival.

\section{References}

1. Lookingbill DP, Spangler N, Helm KF (1993) Cutaneous metastases in patients with metastatic carcinoma: a retrospective study of 4020 patients. J Am Acad Dermatol 29: 228-236. [Crossref]

2. Erdemır AT, Atılganoglu U, Onsun N, Somay A (2011) Cutaneous metastases from gastric adenocarcinoma. Indian J Dermatol 56: 236-237. [Crossref]

3. Schwartz RA (1995) Cutaneous metastatic disease. J Am Acad Dermatol 33: 161-182. [Crossref]

4. Brownstein MH, Helwig EB (1972) Patterns of cutaneous metastasis. Arch Dermatol 105: 862-868. [Crossref]

5. Chatni S, Peshwe H (2005) Cutaneous metastases in carcinoma stomach. Indian J Gastroenterol 24: 133. [Crossref]

6. Attili VSS, Bapsy PP, Lokanatha D, Rajashekar H, Ramachandra C (2008) Cutaneous Metastasis in a Case of Carcinoma Stomach. Austral - Asian Journal of Cancer 7: 233-234.

7. Wang JY, Chai CY, Su YC, Soo KM, Huang YS, et al. (2005) Cutaneous metastasis from gastric adenocarcinoma: a case report. Kaohsiung J Med Sci 21: 329-332. [Crossref]

8. Hu SC, Chen GS, Wu CS, Chai CY, Chen WT, et al (2009) Rates of cutaneous metastases from different internal malignancies: experience from a Taiwanese medical center. J Am Acad Dermatol 60: 379-387. [Crossref]

9. Foo KF, Tao M, Tan EH (2002) Gastric carcinoma presenting with cellulitis-like cutaneous metastasis. Singapore Med J 43: 37-38. [Crossref]

10. Michiwa Y, Earashi M, Kobayashi H, Matsuki N (2001) Cutaneous metastases from gastric adenocarcinoma treated with combination chemotherapy producing complete response with long survival. J Exp Clin Cancer Res 20: 297-299. [Crossref]

Copyright: $(02015$ Marwah S. This is an open-access article distributed under the terms of the Creative Commons Attribution License, which permits unrestricted use, distribution, and reproduction in any medium, provided the original author and source are credited. 